\title{
ARTILLERÍA, PERTRECHOS Y REFORMAS EN SANTIAGO DE CUBA, SIGLO XVIII
}

\section{ARTILLERY, SUPPLIES AND FORTIFICATIONS IN SANTIAGO DE CUBA, $18^{\mathrm{TH}}$ CENTURY}

\author{
POR \\ LILYAM PADRÓN REYES*
}

\section{RESUMEN - AbSTRACT}

Durante el proceso de reformas y modernización de la monarquía hispana a lo largo del siglo XVIII juega un papel fundamental el perfeccionamiento de las defensas imperiales en el espacio caribeño, y especialmente en Cuba. En el presente trabajo analizamos las propuestas que se implementarán en la ciudad suroriental de Santiago de Cuba como parte del proceso de renovación y actualización de sus defensas, especialmente en la provisión y el perfeccionamiento de la artillería de sus principales fortificaciones, a partir de las fuentes primarias localizadas en el Archivo General de Indias y el Archivo Nacional de Cuba. Ello nos permitirá contextualizar el modelo defensivo hispano del siglo XVIII de conjunto con el nuevo escenario geopolítico moderno que ubica al Caribe como un espacio natural del poder europeo.

During the process of reforms and modernization of the Hispanic monarchy throughout the $18^{\text {th }}$ century the improvement of imperial defenses in the Caribbean space, especially in Cuba, would play an important role. In the present work we analyze the proposals implemented in Santiago de Cuba as part of the process of renovation and updating of its defenses. From the primary sources located in the General Archive of the Indies and the National Archive of Cuba the provision and improvement of the artillery of its main fortifications will be studied. This will allow us to contextualize the $18^{\text {th }}$ century Hispanic defensive model together with the new modern geopolitical scenario that would place the Caribbean as a natural space of European power.

\section{Palabras Clave - Keywords}

Artillería; arquitectura militar; siglo XVIII; Caribe hispano; fortificaciones.

Artillery; military architecture; $18^{\text {th }}$ century; Hispanic Caribbean; fortifications.

\section{CÓMO CITAR ESTE ARTículo / CitaTion}

Padrón Reyes, L. (2021): «Artillería, pertrechos y reformas en Santiago de Cuba, siglo XVIII». Gladius, 41: 193-206. https://doi.org/10.3989/gladius.2021.11

\footnotetext{
* Universidad de Cádiz, lilyam.padron@uca.es / ORCID iD: https://orcid.org/0000-0002-8646-584X
} 


\section{INTRODUCCIÓN}

En el transcurso del siglo XVIII ante al conjunto de conflictos, guerras coloniales y pactos que marcan una nueva época de la geopolítica europea, el Caribe jugará un rol determinante en la gobernanza de los imperios atlánticos modernos (Elliot, 2006). En tal sentido, los tráficos de información (personas, ideas, políticas y defensas) conectarán ambos lados del Atlántico y servirán para nutrir y reconocer los planes y estrategias que reforzarán la estabilidad de las monarquías europeas (Leonard y Pretel, 2015).

Si bien como parte de la estrategia defensiva del monarca español Felipe II desde mediados del siglo XVI se levantan las llamadas "piedras para la defensa", a partir de la construcción de fortalezas, castillos y baterías en sus principales plazas y puertos encargados del resguardo y traslado de las riquezas americanas hacia la metrópoli (Ramos Zúñiga, 1993: 50). A partir del fin de la Guerra de Sucesión Española, y la ruptura de poder entre España, Francia e Inglaterra se inaugurará una nueva época que tendrá como principal condicionante la latente amenaza inglesa y sus intereses económicos sobre el Nuevo Mundo, especialmente el hispano (Zapatero, 1990; Cañizares-Esguerra, 2018).

Con la articulación inicial de un vasto plan de fortificaciones iniciales que agrupará los enclaves portuarios de La Habana, Veracruz, Campeche, San Juan, Portobelo y Cartagena de Indias, la Corona hispana intentará asegurar sus territorios en América de las amenazas externas que suponían el resto de Estados europeos, que excluidos del reparto americano apelarían a recursos como el corso y la piratería para hacerse presentes en el escenario atlántico (Cámara Muñoz, 1989). Bajo las nuevas premisas defensivas, las plazas fuertes americanas serán construidas a partir de los condicionamientos en que los muros y las ciudadelas fijarían las directrices del vivir cotidiano, el desarrollo y su expansión, que marcarán el comportamiento de sus pobladores (Marchena Fernández, 2001: 2). En la medida que las circunstancias externas acrecienten la presión sobre el escenario colonial hispano la intención de la Corona irá encaminada en reforzar sus defensas antillanas a partir de los nuevos establecimientos coloniales en el espacio atlántico de los siglos XVII-XVIII (Mcfarlane, 1992; Martínez Shaw y Alfonso Mola, 1999; Crespo Solana, 2007; Weber, 2009).
Para el caso de la isla de Cuba, con un gran peso en el sistema defensivo insular desde el siglo XVI a partir de La Habana y su papel en la Carrera de Indias, encontramos igualmente la ciudad de Santiago de Cuba, que cobraría desde fines del siglo XVII una puntual importancia en su calidad de frontera imperial tras la ocupación inglesa de Jamaica (1655) (Padrón Reyes, 2020a). Bajo este nuevo escenario el resguardo de la urbe suroriental cubana se plantearía como toda una prioridad para la Corona española en el intento de preservar un equilibrio de poderes en el ámbito caribeño (Castillo Meléndez, 1986: 362-363). Como previsión ante tales peligros los Borbones destinarían cuantiosos recursos a perfeccionar y ampliar la extensa red defensiva de su vasto imperio colonial americano frente a los intereses del resto de potencias europeas, y especialmente Inglaterra.

En este sentido, al estudio del sistema de fortificaciones del Caribe español se han dedicado numerosos estudios, especialmente centrados en los ejemplos de La Habana, Cartagena de Indias, Campeche, Portobelo y Veracruz (Castillo Meléndez, 1986; Gutiérrez y Paolini, 1994; Calderón Quijano, 1996; Ortiz Lanz, 1996; Blanes, 2001; Urdapilleta Caamal, 2014; Luengo, 2017). Pese a ello, consideramos que el estudio de las llamadas zonas marginales o periféricas que determinará la realidad para aquellos territorios excluidos de la Carrera de Indias nos ilustra otro contexto oficial de la Corona hispana para sus territorios americanos; tomando especial consideración en los diversos factores sociales, políticos y económicos que significarán para Santiago de Cuba el perfeccionamiento de su sistema defensivo en el aprovisionamiento de su artillería militar a lo largo del siglo XVIII a través de la encomiable labor del cuerpo de ingenieros militares (Capel et alii, 1988; Castillero Calvo, 2016).

Tomando como base primordial la revisión de fuentes primarias localizadas en el Archivo General de Indias y el Archivo Nacional de Cuba, junto al conjunto de fuentes secundarias, nos centraremos en el análisis de una realidad colonial que al menos, para el contexto cubano, nos permite el estudio de modelo defensivo que en el transcurso del siglo XVIII tendría como principal objetivo conservar la integridad territorial de la Corona hispana ante las nuevas coyunturas estratégicas. De igual forma, pretendemos con nuestro trabajo visibilizar una nueva realidad del espacio colonial cubano y sus actores en la defensa del imperio español. 


\section{FORTIFICACIONES, PROVISIONES Y ORDENANZAS EN EL CARIBE HISPANO: SANTIAGO DE CUBA}

Junto con la construcción y el reforzamiento de baluartes y castillos, un punto importante a tener en cuenta desde inicios del siglo XVIII lo representará la artillería con que serán dotadas cada una de las instalaciones, especialmente a partir del fin de la guerra de sucesión española, cuando el monarca Felipe V determinaría una modernización de sus unidades, y les proveerá de una nueva organización según la nueva concepción ilustrada (Kuethe y Kennet, 2014).

El concepto de defensa heredado desde tiempos de Felipe II urgía ser reemplazado por un modelo más eficaz, que respondiera a las necesidades de controlar las zonas estratégicas americanas Caribe, Río de la Plata y el Pacífico- ante la creciente presión del exterior. Se intentaría, al decir de Carmen Gómez Pérez, no solamente mantener la integridad territorial sino establecer una sólida estructura militar capaz de sostener todo el sistema y el aprovisionamiento defensivo en caso de cualquier ataque foráneo (1997: 43).

Bajo esta nueva concepción, se darán pasos iniciales en regular el calibre y las piezas, que irregularmente hacían inviable el suministro y la logística adecuada a tener en cuenta para la buena conducción de la tropa. Así, en junio de 1718 se dictan las ordenanzas militares que regirán la organización de la nueva artillería, en función de su misión y toda tutelada bajo expresas órdenes reales. Igualmente, se ordenará unificar los calibres de los cañones y de los materiales para su construcción según sus formas, sistemas de identificación, accesorios y herramientas. El objetivo estará centrado en conseguir la máxima eficacia de las piezas, y en el cumplimiento de la misión que hubiesen de efectuar, ya fuese en plaza, campaña, costa o naval (De Lizaur, 2010: 477).

A tono con el impulso defensivo, surgiría la necesidad de contar con un personal cualificado en el manejo de las nuevas técnicas en materia bélica. Asimismo, representará una necesidad que los distintos oficiales contasen con una formación que implementase los nuevos conocimientos, y en la misma medida, proyectasen la formación humana y profesional de los futuros altos mandos. En este sentido, la creación de academias fomentará los nuevos conocimientos a través de los distintos programas de estudio que incluirían una bibliografía especializada donde los propios artilleros exhibirán los avances conseguidos y las nuevas técnicas (Gómez Pérez, 1997).

Bajo esta nueva perspectiva, Felipe $V$ ordenaría la creación de la primera Academia de Artillería y Bombas en 1710 en la ciudad de Cádiz, uno de los puntos costeros españoles mejor relacionados con el comercio indiano desde fines del siglo XVI, y donde en 1717 se traslada la Casa de la Contratación, convirtiéndose en centro de la Carrera de Indias (Kuethe, 2004; Bustos Rodríguez, 2005, 2017). De ahí su consideración como plaza fuerte con un desarrollado sistema de fortificación, que aseguraría a sus vecinos realizar sus actividades comerciales sin peligros del exterior. Entre las materias de estudio en la Academia de Cádiz, podemos señalar, las matemáticas puras, geometría, hidráulica, arquitectura civil, artillería en todos sus ramos, dibujo militar, minas y geografía (Cano Révora, 1994: 24). De esta forma, se organizaría una escuela donde se formarán oficiales, utilizando novedosos métodos científicos en conjunto a las virtudes militares y los conocimientos de la ciencia moderna. Los estudios tendrían una duración de cuatro años (Brisquet y Fuentes, 1997: 266).

No obstante, de las nuevas modificaciones en la península, estas nuevas disposiciones tendrán que ser trasladadas hacia América, donde hasta inicios del siglo XVIII muchas de las instrucciones relacionadas con el tema de la artillería eran trasmitidas de forma empírica o práctica, de acuerdo a las necesidades estratégicas de cada presidio, a falta de que existiesen unas disposiciones formales que instituyesen dichas labores. Siguiendo las nuevas directrices que llegaban desde la metrópoli se comenzará a modificar todo el entramado militar americano, especialmente el personal encargado de manejar las piezas de artillería, y el cuidado de todos los pertrechos y municiones de cara a modernizar todos los ámbitos de la oficialidad en los presidios americanos (Gámez Casado, 2018a).

En la isla de Cuba sus distintos gobernadores, como paso inicial recibirán instrucciones para conformar un pormenorizado inventario de todas las piezas de artillería existentes, con el objetivo de reconocer el estado de los pertrechos y armas con que contaba la plaza en sus distintos escenarios defensivos. Para el caso de Santiago de Cuba, la primera relación de la que tenemos noticias recogerá todos los pertrechos contabilizados en su principal defensa, el castillo del Morro. A través de un pormenorizado informe el gobernador Pedro Ferrer informará 
de la situación de la plaza, con especial énfasis en la carencia de personal especializado en las labores de artillería (Tabla 1); y en la irregularidad del situado proveniente desde Nueva España, que influiría negativamente en que el presidio no contase con todas las plazas suficientes para la defensa, ante la imposibilidad económica de sostener un alto número de hombres. Junto a la relación del castillo del Morro, se remitiría información de todo el servicio del resto de puestos y baterías adyacentes (Fig. 1), con la intención de que el alto mando oficial tuviese conocimiento de las defensas con que contaba la plaza, en caso de cualquier ataque o amenaza foránea.

Tabla 1. Pertrechos, armas y municiones que según las últimas noticias constan en el Castillo San Pedro de la Roca de la Plaza de Cuba (1712). Archivo General de Indias (AGI), Santo Domingo, 408.

\begin{tabular}{|c|c|}
\hline Pertrechos y municiones & Cantidades \\
\hline $\begin{array}{c}\text { Cañones de hierro de varios calibres } \\
(16: 14: 9: 8: 7: 4)\end{array}$ & 16 \\
\hline Fusiles corrientes & 25 \\
\hline Esmeriles de bronce & 2 \\
\hline Mosquetes corrientes & 100 \\
\hline Arcabuces corrientes & 80 \\
\hline $\begin{array}{c}\text { Quintales de pólvora de buena } \\
\text { calidad }\end{array}$ & 296 \\
\hline Quintales de pólvora de mala calidad & 20 \\
\hline Quintales de balas de mosquete y \\
fusil & 80 \\
\hline Balas de artillería & 1000 \\
\hline Pies de cabra de hierro & 12 \\
\hline Lanzas de hierro & 12 \\
\hline
\end{tabular}

En particular, el castillo de San Francisco, con una importante misión de salvaguardar la villa interior y sus pobladores, en caso de que los enemigos burlasen los fortines de la costa, será evaluado por el abandono y la dejadez de sus instalaciones y pertrechos (Tabla 2). En este sentido se enfatizaría en la necesidad de un financiamiento regular con que hacer frente a todas las carencias logísticas y de oficiales especializados en el tema de la artillería.

Las distintas relaciones solicitadas, consecuencia de la nueva reestructuración planteada por la real orden de 18 de julio de 1711, reflejaría el interés oficial por conocer la defensa de su imperio de ultramar, a través de los exhaustivos detalles y planos de cada uno de sus puestos, cas- tillos y fortificaciones, en vista de las necesidades estratégicas del siglo XVIII ${ }^{1}$.

Tabla 2. Relación de las armas, municiones y pertrechos y municiones existentes en el Castillo de San Francisco (1712). AGI, Santo Domingo, 408.

\begin{tabular}{|c|c|}
\hline Armas, pertrechos y municiones & Cantidades \\
\hline $\begin{array}{c}\text { Cañones de á 8 de hierro bien } \\
\text { montados }\end{array}$ & 3 \\
\hline $\begin{array}{c}\text { Cañones de á 5 de hierro bien } \\
\text { montados }\end{array}$ & 1 \\
\hline Cañones de á 3 mal montados & 3 \\
\hline Mosquetes corrientes & 44 \\
\hline Mosquetes no corrientes & 44 \\
\hline Arcabuces corrientes & 100 \\
\hline Lanzas & 50 \\
\hline Balas de artillería & 414 \\
\hline Granadas de hierro & 800 \\
\hline Granadas de vidrio & 30 \\
\hline Quintales de balas mosquetes, \\
arcabuces & 70 \\
\hline Quintales de plomo en pasta & 17 \\
\hline Quintales de pólvora de buena \\
calidad & 44 \\
\hline Quintales de pólvora de mala calidad & 6 \\
\hline Quintal de azufre & 1 \\
\hline Quintal de estaño en barrillas & 1 \\
\hline Quintal de cuerdas viejas & 25 \\
\hline
\end{tabular}

Tabla 3. Relación de las armas, municiones y pertrechos y municiones existentes en el fuerte de

Aguadores (1712). AGI, Santo Domingo, 408.

\begin{tabular}{|c|c|}
\hline Pertrechos y Municiones & Cantidades \\
\hline Cañones muy bien montados & 3 \\
\hline Pedreros de hierros & 1 \\
\hline Cámaras & 2 \\
\hline Balas de cañón & 30 \\
\hline Pólvora & 2 \\
\hline Mosquetes viejos & 3 \\
\hline $\begin{array}{c}\text { Quintal de balas, mosquetes y } \\
\text { arcabuces }\end{array}$ & 1 \\
\hline
\end{tabular}

${ }^{1}$ Relación de las armas, municiones y pertrechos existentes en todos los castillos y fortificaciones del puerto de Cuba. Cuba, 16 de agosto de 1712. (AGI), Santo Domingo, leg. 408, exp. 76, fol. 1-10. 


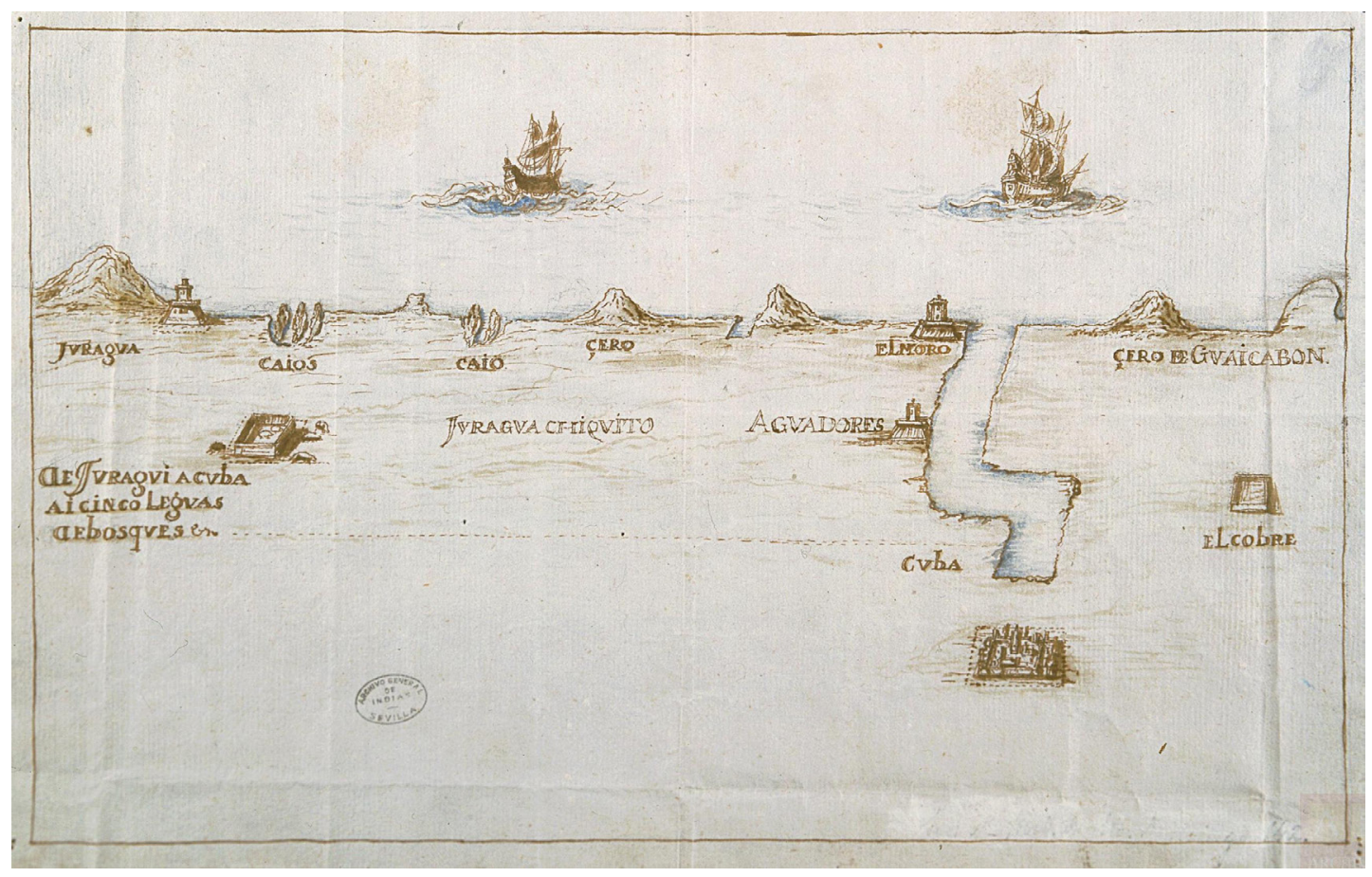

Figura 1. Línea defensiva del puerto de Santiago de Cuba (1692). Archivo General de Indias, MP-Santo Domingo, 103.

Tabla 4. Relación de las armas, municiones y pertrechos existentes en el Fuerte-Batería La Estrella (1712). AGI, Santo Domingo, 408.

\begin{tabular}{|c|c|}
\hline Pertrechos y Municiones & Cantidades \\
\hline Cañones de hierro de 16 & 2 \\
\hline Cañones de hierro de 18 & 2 \\
\hline Cañones de hierro de 20 & 1 \\
\hline Cañones de hierro de 12 & 1 \\
\hline Cañones de hierro de 8 & 1 \\
\hline Cañones de hierro de 6 & 6 \\
\hline Cañones de hierro de 4 & 1 \\
\hline Fusiles corrientes & 5 \\
\hline Mosquetes corrientes & 20 \\
\hline Arcabuces corrientes & 20 \\
\hline Quintales de balas de mosquete y & 2 \\
\hline arcabuces & 4 \\
\hline Quintales de pólvora de buena calidad & 1 \\
\hline Quintales de cuerdas & 400 \\
\hline Balas de artillería &
\end{tabular}

En 1738, cuando la amenaza británica asome con fuerza sobre la ciudad de Santiago de Cuba, el gobernador Cajigal de la Vega, no escatimará recursos económicos en perfeccionar el sistema defensivo de la villa suroriental. Precisamente, uno de los puntos más interesantes en sus peticiones a la Corona giraría en torno a la proyección de la artillería, y en reconocer que

... se carece de ingenieros y artilleros, pues solo hay veinte sin oficial, ni sargentos, y para tanto fuerte, es indispensable algún aumento, y el más reducido que pueda haber será de cuarenta, con oficial inteligente en la profesión, para que ejercite y habilite a los cuarenta artilleros de que se puede formar compañía con sus correspondientes oficiales para el servicio y guarnición de las fortalezas y castillos ${ }^{2}$.

Precisamente, en el informe remitido por sus autoridades registra la deficiente cifra de artilleros con que contaba la plaza, reconocidos en unos veinte hombres, de los cuales la mitad desarrollaban sus labores en el castillo del Morro, y el resto estarían distribuidos por el resto de puestos adyacentes (Agua-

2 El gobernador Francisco Cajigal de la Vegada da razón del estado de los soldados, oficiales, pertrechos y municiones existentes en aquel presidio de Cuba. Santiago de Cuba, 10 de junio de 1738. AGI, Santo Domingo, leg. 450, exp. 32. 


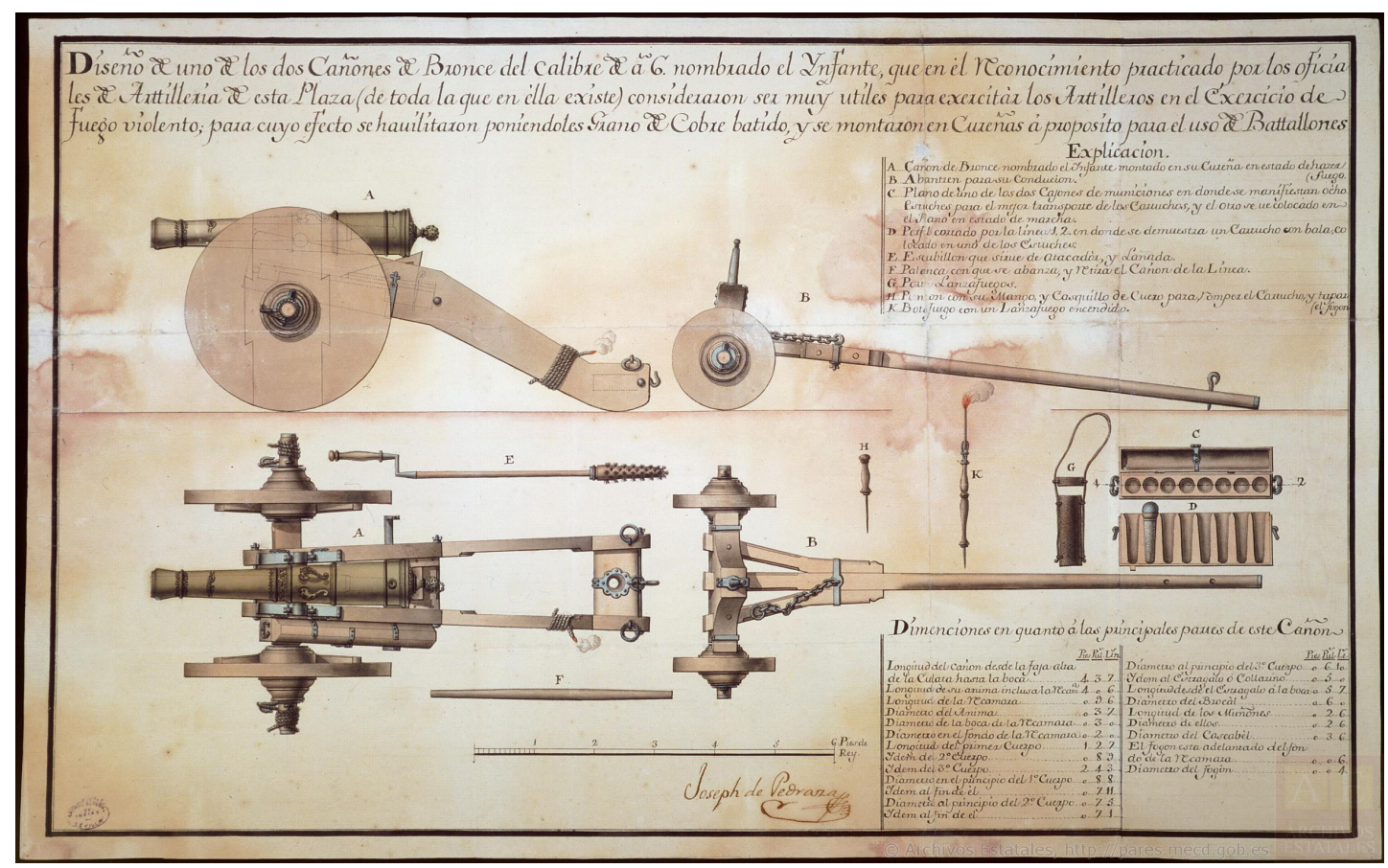

Figura 2. Diseño de uno de los cañones de bronce del calibre de a 6. Archivo General de Indias, MP-Ingenios, 29.

dores y La Estrella). Si analizamos las cantidades y calidades declaradas con especial interés en la nota al pie donde registrarán que de las 77 piezas de artillería (cañones), de varios calibres (36:20:16:9:6:2), solo había una de bronce de dos calibres, el resto eran de hierro, muy antiguas, y desgastadas con la humedad del mar llegando a presentar un alto grado de afectación ${ }^{3}$. En este sentido, el aprovisionamiento de cañones pasaría desde el abastecimiento y la modernización de las piezas desde la península, donde las fábricas más importantes localizadas en Sevilla, Barcelona y Cádiz desde el siglo XVI, van a ser las encargadas de fabricar todo el armamento y la munición con destino hacia América (Fig. 2) (De Ocerín, 1972; Cipolla, 1979; Vigón, 2014; Gámez Casado, 2018a).

No obstante, de los numerosos reglamentos y ordenanzas militares que se llevarían a efecto desde 1718, 1728 y 1743, donde se establecen las piezas y las normas en cada puesto, las circunstancias demostrarían que el presidio de Cuba se encontraba lejos de conseguir un rendimiento óptimo de sus recursos. En buena parte, sus au-

${ }^{3}$ Estado de la artillería del puerto de la ciudad de Cuba. Santiago de Cuba, 6 de mayo de 1738. AGI, Santo Domingo, leg. 450 , exp. 98 , fol. $1-15$. toridades atribuirían las deficiencias logísticas a la carencia de un personal especializado, y el mal estado del almacenamiento de los pertrechos, siendo prácticamente imposible su mantenimiento y cuidado al no contar con una infraestructura apropiada de sus fortalezas, que permitiese la amplitud suficiente para el desplazamiento de las piezas con soltura. (Fig. 3).

Tabla 5. Estado de las armas y municiones existentes en los reales almacenes de la plaza de Santiago de Cuba (1753). AGI, Santo Domingo, 2110.

\begin{tabular}{|c|c|c|c|c|}
\hline Puestos & $\begin{array}{c}\text { Ca- } \\
\text { nones }\end{array}$ & $\begin{array}{c}\text { Balas de cañón } \\
\text {-todos los calibres }\end{array}$ & $\begin{array}{c}\text { Fu- } \\
\text { siles }\end{array}$ & $\begin{array}{c}\text { Bayo- } \\
\text { netas }\end{array}$ \\
\hline $\begin{array}{c}\text { Castillo del } \\
\text { Morro }\end{array}$ & 9 & 969 & 536 & 523 \\
\hline $\begin{array}{c}\text { Castillo de } \\
\text { S. Francisco }\end{array}$ & 62 & 18 & 300 & 600 \\
\hline Cabañas & 9 & 196 & & \\
\hline Aguadores & 17 & 217 & & \\
\hline Jurágua & 5 & 111 & & \\
\hline Juraguacito & 17 & 192 & & \\
\hline Guaicabón & 2 & 22 & & \\
\hline Total & 121 & 1725 & 836 & 1123 \\
\hline
\end{tabular}

Pese a todas las anteriores deficiencias, durante el asedio inglés de Vernon y Knowles (1739- 


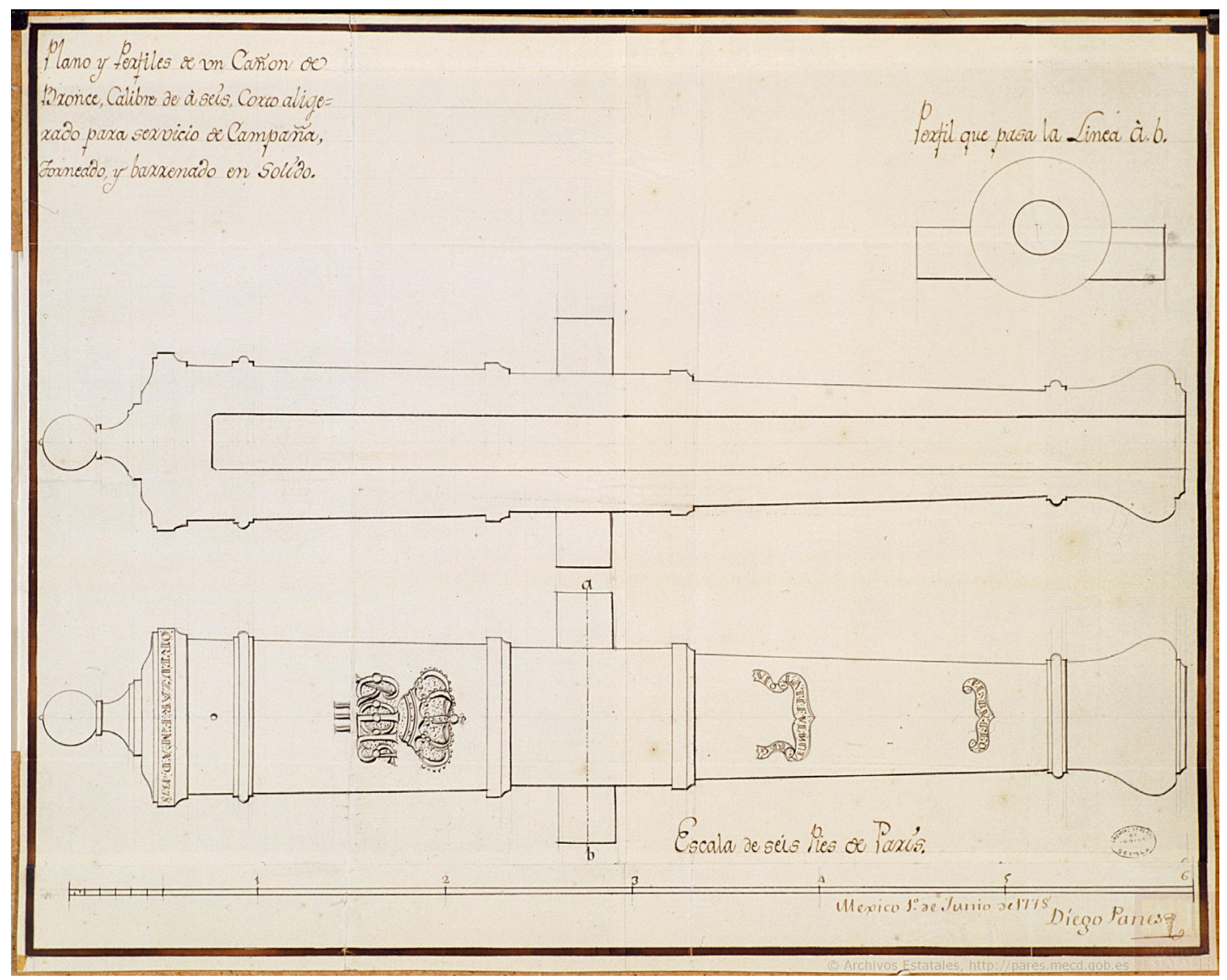

Figura 3. Plano y perfiles de un cañón de bronce, calibre de a seis, corto aligerado para servicio de campaña, torneado y barrenado en sólido, 1778. AGI, MP-MEXICO, 348.

1748), la plaza de Cuba consigue hacer frente al poderoso enemigo, y sus fortificaciones llegaron a estar en defensa ante la amenaza (López Hernández, 2019). La importante estrategia desarrollada por el gobernador Cajigal de la Vega, en conjunto con los cuerpos de milicias desplegados por la región suroriental alcanzaría la victoria, pese a no disponer de grandes recursos en la proyección de su artillería (Padrón Reyes, 2020b).

A partir de 1753 se darán los primeros pasos en un intento centralizador de la Corona por establecer un reglamento para las guarniciones, castillos y fuertes de la jurisdicción de La Habana, Santiago de Cuba y San Agustín de la Florida. Tales iniciativas tendrán materialización en la gestión del Conde de Revillagigedo, virrey de la Nueva España en establecer una importante reforma del organigrama defensivo, con un particular interés por sustituir las viejas compañías de presidio por modernas unidades, regimientos y batallones en cada una de las plazas indicadas normalizando los oficiales, las unidades de cada arma, el modo de financiarlas, y el sueldo de los oficiales tomando en consideración las cifras del situado destinado para cada una de estas ciudades y el financiamiento de sus defensas (Marichal y Grafenstein, 2013).

En el primer punto, se constituirá que el servicio de cada una de las plazas y sus puestos adyacentes deberán estar conformados por

...un regimiento de infantería de cuatro batallones de seis compañías cada una, cinco de fusileros de noventa y cuatro soldados, incluidos dos sargentos, dos tambores; y una de granaderos de cincuenta, con los mismos sargentos, y un tambor: una compañía de artilleros, y cuatro de dragones en la forma, que se expresará sucesivamente después de reglado, y establecido lo que corresponde, y pertenece a 
la plana mayor de aquella plaza, sus castillos, fuertes, y puestos de su jurisdicción ${ }^{4}$.

Con la implementación de tales disposiciones, la Corona sentaría las bases de un verdadero ejército de dotación para la defensa de América en cada uno de sus territorios. La vertebración del conjunto de unidades locales al mando de un estado mayor, significará la centralización de un modelo costoso y poco viable en buena parte de las poblaciones americanas debido a la lejanía y nula comunicación entre ambas partes en los momentos de crisis. La solución planteada por el conde de Revillagigedo, modificará los aspectos relacionados con los salarios de sus oficiales de base de acuerdo a sus obligaciones y responsabilidades. Para el caso particular de Santiago de Cuba se plantearía equiparar el salario y las funciones de sus oficiales bajo las mismas calidades que las declaradas en La Habana, respetándose siempre el caudal existente en sus cajas reales ${ }^{5}$.

\section{LA MATERIALIZACIÓN DE UN NUEVO MODELO DEFENSIVO, 1766-1799}

Con la llegada a la isla de Cuba del Conde de Ricla y del mariscal de campo Alejandro O'Reilly a partir de 1766, se implementarán numerosas reformas administrativas, políticas y militares, y se darán importantes pasos en el reforzamiento y modernización del sistema defensivo de La Habana y Santiago de Cuba. En particular, asumirán la importante misión de estudiar y confeccionar un plan de defensa que certificase a la Corona que los sucesos ocurridos en La Habana no tuviesen continuidad en ningún otro momento.

En particular, el cuerpo de ingenieros tendrían a su cargo el estudio y construcción de un moderno sistema en el plano de la artillería, donde retomando la experiencia europea se ejecutarían mejoras al sistema de Vauban, proyectándose trincheras de apoyo cada vez más cercanas a las murallas, y por consiguiente la artillería se ubicará en puntos

\footnotetext{
${ }^{4}$ Reglamento para la guarnición de La Habana, castillos y fuertes de su jurisdicción, Santiago de Cuba y San Agustín de la Florida. México, 8 de abril de 1753. AGI, Santo Domingo, leg. 2110, exp. 74.

${ }^{5}$ Don Juan Francisco Güemes, Conde de Revillagigedo, virrey de la Nueva España modifica algunos puntos del reglamento para las plazas de Habana, Santiago de Cuba y La Florida. México, 30 de agosto de 1754. AGI, Santo Domingo, leg. 2110 , exp. 45.
}

cada vez más cercanos, con el objetivo de alcanzar mejores ángulos a batir al enemigo, teniendo en cuenta las circunstancias en el abastecimiento de víveres y municiones, así como la posibilidad de recibir refuerzos (De Lizaur, 2010: 481).

El potencial defensivo atesorado en los puestos adyacentes de Aguadores, Cabañas y Jurágua vendría a confirmarnos cómo se irá consolidando el nuevo modelo planteado desde la península para prevenir al enemigo de batir las cortinas y baluartes de la plaza según las tácticas de asedio sobre todo usadas en Europa (López Hernández, 2019: 195). Siendo así, los fuertes y baluartes secundarios jugarán un papel decisivo en resguardar la entrada de la bahía de Santiago de Cuba, y servir de vanguardia en caso de cualquier ataque atendiendo a la dotación de su artillería ${ }^{6}$.

Tabla 6. Inventario de la artillería y municiones en los puestos de Aguadores y Cabañas en el puerto de Santiago de Cuba (1762). Archivo Nacional de Cuba, Correspondencia de los Capitanes Generales, leg. 11, exp. 154 .

\begin{tabular}{|c|c|c|c|c|}
\hline Puestos & Cañones & $\begin{array}{c}\text { Balas de } \\
\text { todos los } \\
\text { calibres }\end{array}$ & Rifles & Pólvora \\
\hline Aguadores & 17 & 207 & 6 & $\begin{array}{c}8 \\
\text { quintales }\end{array}$ \\
\hline Cabañas & 11 & 125 & 9 & $\begin{array}{c}6 \\
\text { quintales }\end{array}$ \\
\hline Totales & 28 & 332 & 15 & $\begin{array}{c}14 \\
\text { quintales }\end{array}$ \\
\hline
\end{tabular}

Luego del terrible terremoto sufrido en la ciudad a fines de 1766 , con severos daños a todo su cinturón defensivo, se tomarán providencias desde el mando central para poner a efectos nuevamente sus defensas, y bajo tales encargos serán destinados numerosos ingenieros militares entre 1766-1771, donde destacarían nombres como: Agustín Crame, Francisco de Langle y Francisco Calderín; quienes estudiarán y propondrán a la Corona numerosas mejoras que debían realizarse en cada uno de sus baluartes arruinados (Cruz Freire y López Hernández, 2017) 7 .

\footnotetext{
${ }^{6}$ Carta del gobernador de Santiago de Cuba Fernando Cajigal dirigida a Alejandro O'Reilly informando acerca del proyecto de fortificar las inmediaciones de la plaza. Santiago de Cuba, 14 de marzo de 1764. Archivo Nacional de Cuba (ANC), Correspondencia de los Capitanes Generales, leg. 14, exp. 77.

${ }^{7}$ Puntos acordados entre el gobernador de la plaza de Cuba, y el ingeniero en jefe de ella para su mejor resguardo.
} 


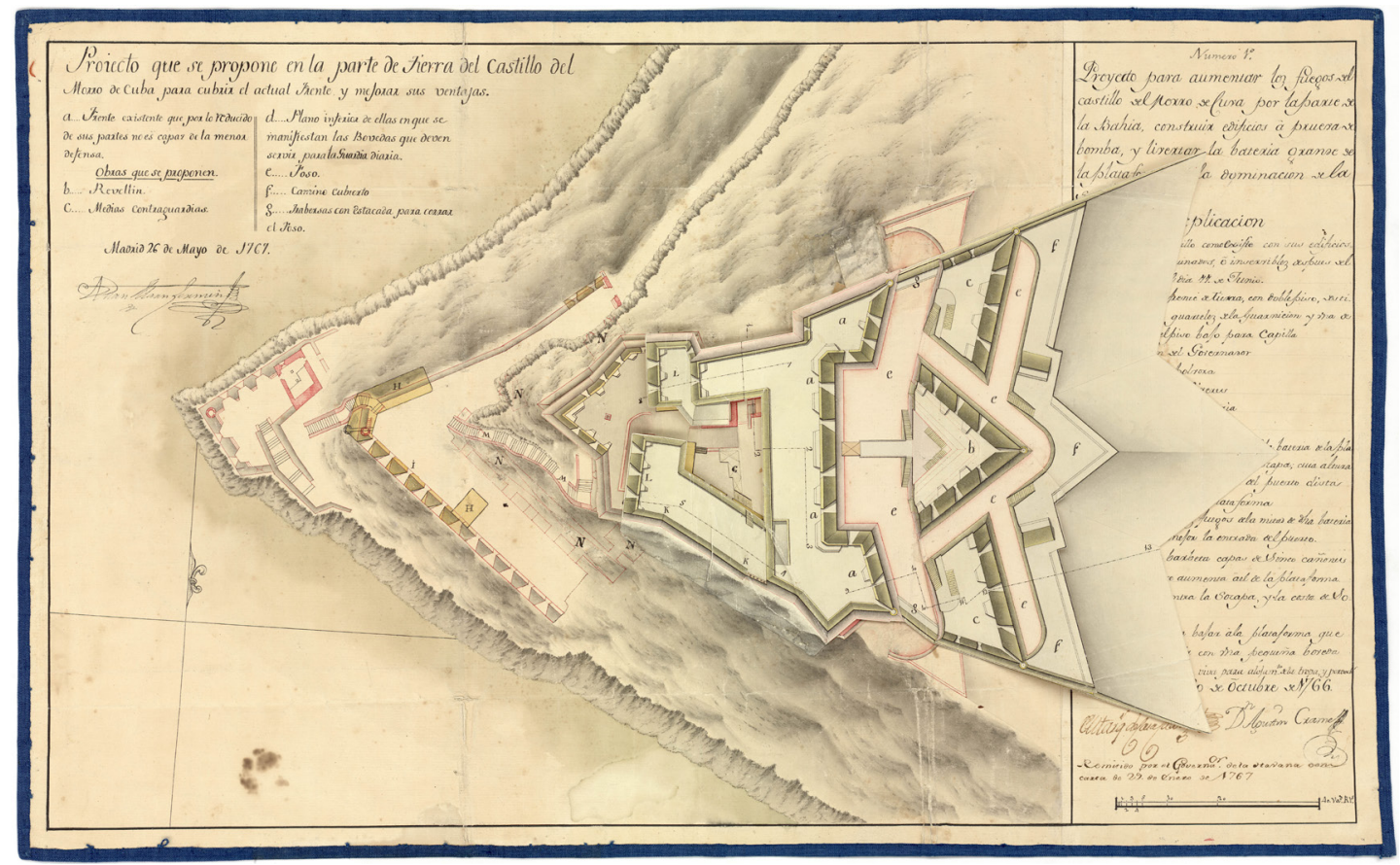

Figura 4. Proyecto para aumentar los fuegos del castillo del Morro de Santiago de Cuba. Archivo Cartográfico de Estudios Geográficos del Centro Geográfico del Ejército, Ar. J-T.10-C.2-306.

Tabla 7. Inventario de la artillería, municiones y muebles en el puesto de Jurágua (1762). Fuente: ANC, Correspondencia de los Capitanes Generales, leg. 11, exp. 154. Santiago de Cuba, 16 de septiembre de 1762.

\begin{tabular}{|c|c|}
\hline Artillería y Municiones & Cantidades \\
\hline Cañones de todos los calibres & 16 \\
\hline Rifles & 12 \\
\hline Balas & 304 \\
\hline Cartuchos & 358 \\
\hline Muebles & \\
\hline Botijas & 2 \\
\hline Escaños & 2 \\
\hline Sillas & 2 \\
\hline Mesa & 1 \\
\hline Catres & 2 \\
\hline Puertas & 2 \\
\hline Cepo & 1 \\
\hline & \\
\hline &
\end{tabular}

Precisamente, entre los puntos que tendrán especial incidencia para la reactivación de la plaza,

Cuba, 4 de enero de 1771. AGI, Papeles de Cuba, leg. 1067, exp. 56 , fol. 1-10. enfatizarán los relativos a la ubicación y construcción de los almacenes de pertrechos, municiones y artillería, así como el perfeccionamiento de los ángulos de fuego del castillo del Morro. Para el primero se determinará como solución que se construyeran los almacenes de víveres y pertrechos con materiales más resistentes a los continuos sismos. Especialmente, el ingeniero en jefe Silvestre Abarca recomendaría al gobernador Oloriz, «que se tomen todas las precauciones para asegurar la pólvora con motivo de estar al descubierto, y en caso de cualquier acción enemiga resguardarla en el castillo principal $»^{8}$.

Es decir, la propuesta vendrá encaminada en la mejora de los materiales y en una nueva colocación para su almacenamiento, que será materializada en los posteriores trabajos a cargo del ingeniero Ventura Buzeta. Sobre el perfeccionamiento de los fuegos del castillo del Morro se propuso aumentar su potencial por el frente de mar en su bahía, además de construir nuevos compartimentos en la fortaleza a prueba de bombas. Junto a ello, la plaza de armas quedará estructurada en

${ }^{8}$ Puntos acordados. AGI, Papeles de Cuba, leg. 1067, exp. 56 , fol. 5 . 


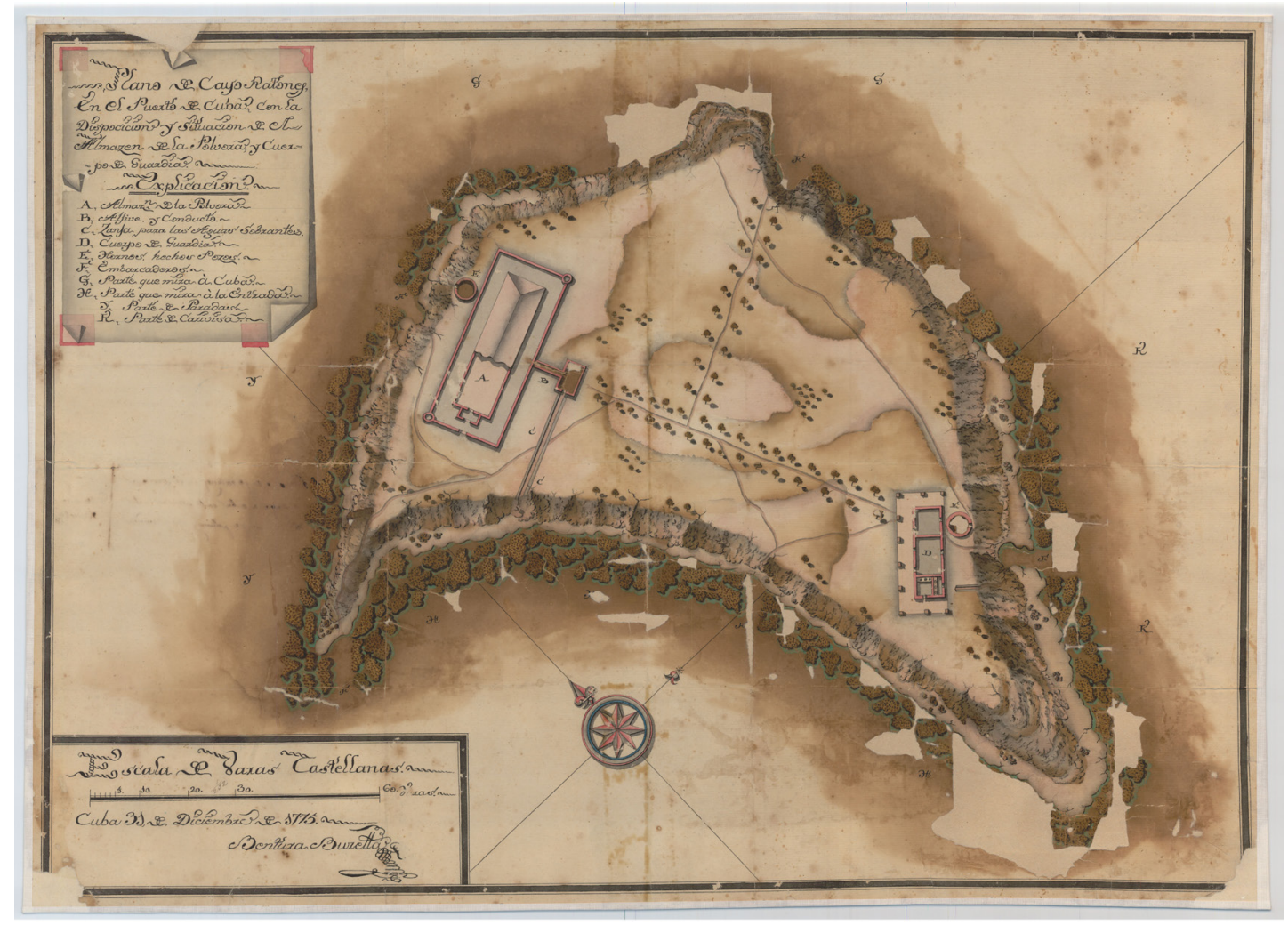

Figura 5. Ubicación del almacén de pólvora en Cayo Ratones proyectado por el ingeniero militar Ventura de Buzeta (1775). Archivo Histórico Militar de Madrid (AHMM), Cuba 95/2.

diferentes niveles adaptados a la topografía del terreno, unidos por escaleras y rampas, donde se localizarán almacenes de pólvora, pertrechos, armerías, puesto de guardia, cocina y una capilla. Los baluartes se unirán mediante cortinas o lienzos rectos de murallas para hacer frente al uso de la artillería (Arcos Martínez, 2010: 55).

Asimismo, en 1775 el ingeniero militar Ventura Buzeta, destinado en la plaza de Cuba, proyectará lo que a su entender era de vital necesidad para la mejora de sus fortines y baterías, con la edificación de un polvorín, en el islote ubicado en el centro de la bahía, a modo de que sirviese en el abastecimiento de municiones, pólvora y cuartel de tropas. De esta forma se daba cumplimiento a las indicaciones reales de poner "en defensa" todo el cinturón defensivo, aprovechando las numerosas ventajas naturales y geográficas del entorno costero. A pesar de que en la misma medida sus condiciones naturales de humedad y alta salinidad actuarán como catalizadores de que las numerosas piezas de artillería presentasen deficiencias y desgastes, en particular la madera de sus cureñas.
Para abril de 1778, en la relación acerca del estado de la plaza remitida por el gobernador se resaltará que su castillo principal se hallaba en total defensa,

...y por su elevada situación por la artillería regular, aunque en corto número y bondad de sus murallas, sirviéndole de escudo las baterías de la plataforma, más bajas y rasantes, sus cañones de grueso calibre, y bien situados: si con el defecto de sus parapetos poco robustos y la enfilada de la Socapa'.

Junto con el reforzamiento arquitectónico de sus distintas fortalezas, la Corona dispondría la creación de un Cuerpo especializado en el tema de la artillería, que representará uno de los más importantes avances promovidos en América, a partir de la creación en 1731 de la primera Academia de Ingenieros en Cartagena de Indias por

\footnotetext{
9 Relación del estado en que se halla la plaza de Santiago de Cuba con las demás adyacentes baterías y defensas, Santiago de Cuba, 30 de abril de 1778. AGI, Papeles de Cuba, leg. 1230, exp. 38, fol. 1-4.
} 
Juan de Herrera y Sotomayor, que dará impulso en la creación de otras escuelas en la formación de especialistas en la materia en La Habana, Puerto Rico y Nueva España (Marchena Fernández, 1977: 27; Gámez Casado, 2018a: 66).

Tabla 8. Artillería y cureñas del Castillo del Morro (1778). AGI, Papeles de Cuba, leg. 1230.

\begin{tabular}{|c|c|c|c|c|c|c|}
\hline Artillería & $\mathbf{2 4}$ & $\mathbf{1 6}$ & $\mathbf{1 2}$ & $\mathbf{8}$ & $\mathbf{5}$ & Total \\
\hline Cañones (varios calibres) & 4 & 8 & 6 & 1 & 2 & 21 \\
\hline Cureñas & 4 & 4 & 4 & & & 14 \\
\hline
\end{tabular}

En este sentido, se pasará a un cuerpo de técnicos con amplios conocimientos en armas, balística y fuegos, que le harán distinguir de la infantería regular como un grupo distinguido, con un sueldo mayor. Lo que, al entender de Juan Marchena, aumentará los costes de la defensa, y conllevará que las plazas americanas dependientes del financiamiento regular en forma de situados se vean imposibilitadas en sostener tan altos costes (1979: 87). Ello incidiría en que se acuda a soluciones alternativas de acuerdo a las condiciones sociales y económicas de cada territorio. De esta forma, en la plaza de Cuba según reflejan las informaciones en el plan de defensa articulado para la ciudad por el gobernador Joseph Tentor en 1778, encontramos una elevada cifra de personal, que declarados como "negros artilleros" -348 hombres- distribuidos en los distintos puestos defensivos a sotavento y barlovento de la costa santiaguera tendrán bajo su responsabilidad el cuidado y manejo de la artillería $^{10}$.

Todo ello nos hace suponer que, como solución en la escasez de efectivos, y ante la imposibilidad de mantener los altos sueldos, los dirigentes locales tomarán la determinación de utilizar negros de las Minas de Santiago del Prado, que bajo la condición de "esclavos del rey" serían utilizados junto con los indios de Los Caneyes y San Pablo de Jiguaní en prestaciones para la defensa (Díaz, 2000). En este sentido, la inclusión de sectores populares en actividades tan estratégicas bajo el mando de un cuerpo especializado que se encargarían de velar que cumpliesen con sus de-

10 Plano que demuestra el estado de defensa en caso de ser atacada la plaza de Cuba, dispuesto por su gobernador D. Joseph Tentor. Santiago de Cuba, 15 de junio de 1778. AGI, Papeles de Cuba, leg. 1230, exp. 10. beres operativos, y mostrarían los diferentes modelos y prácticas coloniales utilizadas en cada uno de los espacios americanos, así como las distintas soluciones de cara al mantenimiento y adaptación de un modelo de defensa global (Baeza Martín, 2005; Kuethe y Marchena, 2005; Padrón Reyes, 2016).

Al decir de Goeffrey Parker, la "superioridad técnica", en sí misma, rara vez ha sido un elemento suficiente para alcanzar la victoria; sin embargo, de conjunto con disciplina y el sentido corporativo serán componentes fundamentales en una formación militar para resistir al enemigo, tanto cuando ataca como cuando es atacado (2010: 8-9). Asimismo, un elemento fundamental para contrarrestar el avance del enemigo en caso necesario serán las distintas compañías de milicias disciplinadas, que organizadas desde 1767 reforzarán la protección de la ciudad en tiempos de guerra, y ante cualquier eventualidad ${ }^{11}$. Todo ello, teniendo como eje central el perfeccionado sistema de fortificaciones cuyo eje central será el castillo del Morro o San Pedro de la Roca a la entrada de su bahía, y cuya posición permitía enfilar cualquier embarcación que intentase forzar la entrada de su puerto.

De esta forma, se nombrará como comandante del castillo al teniente coronel Isidro de Limonta, quien se había desempeñado desde 1741 en las distintas acciones combativas de la plaza, y había ayudado en las labores de reconstrucción de las fortificaciones a los ingenieros militares. Ello asegurará a la Corona que el control y la defensa de uno de sus principales puntos estratégicos en el Caribe quedasen a buen resguardo, y bajo una figura de garantía para su puntual conducción según los tiempos que advertía el panorama americano para la conducción del orden colonial ${ }^{12}$.

En 1790, se realizarán nuevas mejoras según lo proyectado por el ingeniero militar Francisco

${ }^{11}$ La plaza de Cuba para fines del siglo XVIII contará con un cuerpo de milicias disciplinadas de 4 compañías: dos de infantería, una de caballería, y otra de pardos-morenos alcanzando una cifra de 1300 hombres según estimaba en 1780 el gobernador Antonio de Salas. Ver: Extractos de las revistas de Inspección de las compañías de milicias establecidas en la ciudad de Cuba por el gobernador Antonio de Salas. Santiago de Cuba, 20 de febrero de 1780. AGI, Papeles de Cuba, leg. 1183, exp. 45.

12 Relación de méritos y servicios del teniente coronel Isidro de Limonta comandante del castillo del Morro de Santiago de Cuba. Santiago de Cuba, 20 de octubre de 1780. AGI, Papeles de Cuba, leg. 1231, exp. 34. 
Suárez Calderín - amplio conocedor del terreno santiaguero- en lo relativo a la ubicación de nuevas cortaduras que asegurasen la dificultad del enemigo para su acceso al castillo del Morro. Constituiría una premisa para la Corona que sus posesiones coloniales dispusieran de un eficaz sistema de defensas que estuvieran a tono con las nuevas doctrinas de fortificación y estuvieran identificadas dentro de los nuevos resortes estratégicos derivados de la geopolítica imperial hispana (Ramos Zúñiga, 1993: 52-53).

Con un sistema defensivo perfeccionado según los nuevos adelantos científicos y tácticos la isla de Cuba representará una garantía de seguridad para la Corona hispana en el Caribe. A partir de la política defensiva establecida se articularía una estrategia basada en potentes fortificaciones, capaces de resistir a la hegemonía inglesa con un mínimo de personal y recursos.

\section{CONSIDERACIONES FINALES}

Al iniciar el siglo XVIII, y a partir del cambio dinástico en España, un nuevo período de conflictos y reformas asomaría sus luces sobre la América hispana. En el intento de un mayor y mejor control sobre sus territorios coloniales, se adoptarán una serie de medidas y políticas ilustradas, que pondrán de manifiesto su interés por conocer a profundidad el funcionamiento económico, político y militar del imperio, a la vez, que intentarán frenar el avance británico sobre el mercado americano.

Tras los acontecimientos que tienen lugar a partir de 1763, con las negociaciones de paz entre España e Inglaterra tras la toma de La Habana, la Corona hispana dará luz verde a un proceso de reformas, que para la ciudad de Santiago de Cuba significarían la revalorización de su sistema defensivo, a fin de ponerle "en defensa" ante la amenaza que suponía su cercanía geográfica con Jamaica (Padrón Reyes, 2018).

Las nuevas directrices serían gestionadas y supervisadas por un especializado grupo de ingenieros militares que formados en las academias militares tendrán a su cargo la importante misión de perfeccionar y adaptar el entorno defensivo caribeño según las nuevas transferencias científicas y militares que marcan el reformismo borbónico. De esta forma, a partir de 1766, la bahía santiaguera inicia todo un complejo proceso, que ejecutado en varias etapas conseguiría estructurar un plan de defensa local, sustentado en las mejoras estratégicas que trasladan a la capital suroriental la concepción del arte militar ilustrado basado en la mejora de su artillería, y en el máximo aprovechamiento de sus ventajas naturales siempre advirtiéndose que las acciones desarrolladas representasen el menor perjuicio económico para los intereses reales. La Corona enfatizaría en la importancia de una mejor centralidad política y militar, y en este sentido, las acciones irán encaminadas en fortalecer la presencia oficial, con el fin de frenar el comercio ilícito y reestructurar sus relaciones de poder con el territorio en cuestión.

Con un sistema defensivo perfeccionado según los nuevos adelantos científicos y tácticos la plaza de Cuba, en conjunto con La Habana representarán una garantía de seguridad para la Corona hispana en el Caribe (Luengo, 2017; Gámez Casado, 2018a), y particularmente en la isla de Cuba; a través de un modelo defensivo que responde al principal objetivo de preservar la soberanía del imperio español en la considerada "frontera política" ante el posicionamiento inglés en el espacio antillano.

\section{BIBLIOGRAFÍA}

Arcos Martínez, N. (2010): El ingeniero militar ilustrado Agustín Crame y el reordenamiento defensivo en el Caribe (1777-1779). Tesis Doctoral (inédita), México, UNAM.

Baeza Martín, A. (2005): «Fundición de Artillería en Nueva España: proyectos fallidos, la alternativa a Sevilla (1722-1794)», A. Gutiérrez Escudero y M. L. Laviana Cuetos (coords.), Estudios sobre América. Siglos XVI-XX. Sevilla, Asociación Española de Americanistas: 879-904.

Blanes Martín, T. (1989): «Las fortificaciones coloniales de la ciudad de La Habana». Arquitectura Cuba, 370: 17-39.

Brisquet Torres, M. y Fuentes Legaz, E. (1997): «Las Academias de Artillería en América en el siglo XVIII». Militaria. Revista de Cultura Militar, 10: 265-276

Bustos Rodríguez, M. (2005): Cádiz en el sistema atlántico moderno: la ciudad, sus comerciantes y la actividad mercantil (1650-1830). Madrid, Editorial Sílex.

Bustos Rodríguez, M. (2017): El Consulado de cargadores a Indias en el siglo XVIII (1700-1830). Cádiz, Servicio de Publicaciones de la Universidad de Cádiz.

Calderón Quijano, J. A. (1996): Las Fortificaciones españolas en América y Filipinas. Madrid, Mapfre. 
Cámara Muñoz, A. (1989): «La fortificación de la monarquía de Felipe II». Espacio Tiempo y Forma. Serie VII. Historia del Arte, 2: 73-80. https://doi. org/10.5944/etfvii.2.1989.2143

Cano Révora, M. G. (1994): Cádiz y el Real Cuerpo de Ingenieros Militares (1697-1847). Cádiz, Servicio de Publicaciones Universidad de Cádiz.

Cañizares-Esguerra, J. (Ed.). (2018): Entangled Empires: The Anglo-Iberian Atlantic, 1500-1830. The Pennsylvania University Press.

Capel, H.; Sánchez, J. E. y Moncada, O. (1988): De Palas a Minerva: la formación científica y la estructura institucional de los ingenieros militares en el siglo XVIII. Madrid, CSIC.

Castillero Calvo, A. (2016): Portobelo y el San Lorenzo del Chagres. Perspectivas imperiales. Siglos XVI$X I X$. Panamá, Editora Novo Art.

Castillo Meléndez, F. (1986): La defensa de la Isla de Cuba en la segunda mitad del siglo XVII. Sevilla, Diputación Provincial de Sevilla.

Cipolla, C. M. (1979): Cañones y velas en la primera fase de la expansión europea: 1400-1700. Barcelona, Editorial Ariel.

Crespo Solana, A. (2007): «Flandes y la expansión mercantil europea», Flandes y Canarias. Las Palmas, Centro de la Cultura Popular Canaria: 13-83.

Cruz Freire, P. y López Hernández, I. J. (2017): Ingeniería e ingenieros en la América hispana: siglos XVIII-XIX. Sevilla, Servicio de Publicaciones de la Universidad de Sevilla.

De Lizaur y De Utrilla, A. (2010): La ilustración en Cataluña: la obra de los Ingenieros Militares. Madrid, Ministerio de Defensa.

De Ocerín, E. (1972): Apuntes para la historia de la fábrica de Artillería de Sevilla. Sevilla.

Diaz, M. E. (2000): The Virgin, the King and The Royals Slaves: Negotiating Freedom in colonial Cuba, 1670-1790. Stanford University Press.

Elliott, J. (2006): Empires of the Atlantic World: Britain and Spain in America, 1492-1830. New Haven y Londres, Yale University Press.

Gámez Casado, M. (2018a): «Cañones al óleo. Una alternativa para la artillería de Cartagena de Indias a fines del siglo XVIII». Gladius, 38: 159-176. https://doi.org/10.3989/gladius.2018.09

Gámez Casado, M. (2018b): «Cartagena de Indias. La bahía más codiciada», Mares fortificados. Protección y defensa de las rutas de globalización en el siglo XVIII. Sevilla, Servicio de Publicaciones de la Universidad de Sevilla: 59-72.

Gómez Pérez, C. (1997): «El problema logístico y la operatividad de la Artillería en América». Militaria. Revista de Cultura Militar, 10: 43-56.

Gutiérrez, R. y Paolini, R. (1994): El Caribe fortificado. Buenos Aires, Ediciones Uniandes.

Kuethe, A (2004): «La Casa de la Contratación en la época de su traslado a Cádiz», E. Vila Vilar, A. Acosta y A. L. González Rodríguez, La Casa de la
Contratación y la navegación entre España y las Indias. Sevilla, CSIC - Universidad de Sevilla: 205-218.

Kuethe, A. y Kennet, A. (2014): The Spanish Atlantic World in the Eighteenth Century. War and the Bourbon Reforms, 1713-1796. Nueva York, Cambridge University Press.

Kuethe, A. y Marchena, J. (eds.) (2005): Soldados del rey. El ejército borbónico en América colonial en vísperas de la independencia. Castellón de la Plana: Servicio de publicaciones de la Universitat Jaume I.

Leonard, A. y Pretel, D. (eds.) (2015): The Caribbean and the Atlantic World economy. Circuits of Trade, Money and Knowledge, 1650-1914. Cambrigde Imperial \&Post-Colonial Studies.

López Hernández, I. J. (2019): «La defensa de Santiago de Cuba al ataque de Vernon de 1741: Principios de fortificación para la Guerra en el Caribe». Anuario de Estudios Americanos, 76 (1): 177-207. https:// doi.org/10.3989/aeamer.2019.1.08

Luengo Gutiérrez, P. (2017): «Military Engineering in Eighteenth-Century Havana and Manila: The Experience of the Seven Years War». War in History, 24, 1: 4-27. https://doi.org/10.1177/0968344515620829

Marchena Fernández, J. (1977): «La primera Academia de Ingenieros en América». Ejército-Revista de las Armas y Servicios, 447: 23-31.

Marchena Fernández, J. (1979): «La financiación militar en Indias. Introducción a su estudio». Anuario de Estudios Americanos, 36: 81-110.

Marchena Fernández, J. (2001): «El poder de las piedras del Rey. El impacto de los modelos europeos de fortificación en la ciudad barroca americana», Actas del III Congreso Internacional del Barroco Americano: territorio, arte, espacio y sociedad, Universidad Pablo de Olavide, Sevilla, 8-11 de octubre: $82-83$.

Marichal, C. y Grafenstein, J. (2013): El secreto del imperio español: los situados coloniales en el siglo XVIII. México D.F., El Colegio de México - Centro de Estudios Históricos - Instituto Mora.

Martínez Shaw, C. y Alfonso Mola, M. (1999): Europa y la expansión del Nuevo Mundo. Madrid, Editorial Síntesis.

Ortiz Lanz, J. E (1996): Piedras ante el mar. Las fortificaciones de Campeche. México, D.F., Gobierno del Estado de Campeche/Consejo Nacional para la Cultura y las Artes.

Padrón Reyes, L. (2016): «Indios en la defensa marítima del territorio cubano, siglos XVI-XVII». Revista Hispanoamericana, 6: 1-30.

Padrón Reyes, L. (2018): «Santiago de Cuba del abandono al perfeccionamiento en su sistema defensivo, siglos XVII-XVIII». Iberoamérica Social, 2 (especial): 46-62.

Padrón Reyes, L. (2020a): «En los márgenes del imperio: Santiago de Cuba, siglos XVI-XVII», A. Gullón Abao y L. Padrón Reyes (coords.), El valor 
histórico-arqueológico del mar. Santa Marta, Editorial Universidad del Magdalena: 253-277.

Padrón Reyes, L. (2020b): «Conflicto y guerra en el Caribe. Papel desempeñado por las milicias de indios frente al intento de invasión británica a Santiago de Cuba (1739-1748)».Naveg@merica, 24.

Parker, G. (2010): Historia de la guerra. Madrid, Editorial Akal.

Ramos Zúñiga, A. (1993): «La fortificación española en Cuba, siglos XVI-XIX». Atrios, 5: 49-64.
Urdapilleta Caamal, I. (2014): «Más allá de las murallas: el sistema defensivo de Campeche durante el régimen de los Austrias», Indiana, 31: 219-244.

Vigón, J. (2014): Historia de la Artillería Española. Madrid, Editorial Ministerio de Defensa, 3 tomos.

Weber, D. J. (2009): The Spanish Frontier in North America. New Haven and London, Yale University Press.

Zapatero J. M. (1990): La guerra del Caribe en el siglo XVIII. Madrid, Servicio Histórico Militar. 